\title{
Analyzing Information about a Hajj Pilgrimage in Indonesia in the Rare Newspaper Collection of The National Library of Indonesia
}

\section{Analisis Informasi Penyelenggaraan Ibadah Haji di Indonesia dalam Koleksi Surat Kabar Langka Perpustakaan Nasional Republik Indonesia}

\author{
Frial Ramadhan Supratman
}

Paper Type:

Research Paper

\section{Perpustakaan Nasional Republik Indonesia}

\section{Abstract}

Background of the study: Indonesia is a country whose the largest number of Muslims in the world. Every year, many Indonesian Muslims come to Mecca to perform hajj pilgrimage. In order to improve pilgrimage activity, Government and society need exact information about that. The librarian can take an important role in order to supply information about hajj pilgrimage.

Purpose: The aim of research is explaining description and information about Indonesian hajj pilgrims through a collection of rare newspapers in the National Library of Indonesia.

Method: The method used in this research is a descriptive research method. Author analyzes twenty two newspapers in National Library. Having been analyzed, the information obtained is interpreted by historical approach.

Findings: The result of this research is that the author finds out 22 newspapers which contains information of hajj pilgrims. The information is qualitative data on the amount of hajj pilgrims and ships, the expense of hajj pilgrimage, the experience of hajj pilgrims, the problem faced by hajj pilgrims and government policy in controlling hajj pilgrims.

Conclusion: In this paper, the author argues that rare newspaper collection contains many information about the activity of the hajj pilgrimage during Dutch colonial period.

Keywords: Hajj pilgrims, National Library of Indonesia, rare newspapers. 


\begin{abstract}
Abstrak
Latar Belakang: Indonesia merupakan negara dengan jumlah Muslim terbesar di dunia. Setiap tahun, banyak Muslim Indonesia yang datang ke Mekah untuk menunaikan ibadah haji. Untuk mendukung penyelenggaraan ibadah haji, pemerintah dan masyarakat tentu saja memerlukan informasi yang tepat. Pustakawan dapat berkontribusi dengan memberikan informasi mengenai penyelenggaraan ibadah haji.

Tujuan: Tujuan penelitian ini adalah memberikan gambaran dan informasi mengenai jamaah haji Indonesia melalui sumber surat kabar langka koleksi Perpustakaan Nasional Republik Indonesia.

Metode: Metode yang digunakan dalam penelitian ini adalah metode deskriptif. Penulis melakukan analisis terhadap 22 surat kabar di Perpustakaan Nasional Republik Indonesia. Setelah dianalisis, informasi tersebut diinterpretasi menggunakan pendekatan ilmu sejarah.

Hasil: Hasil dari penelitian ini adalah penulis menemukan 22 surat kabar yang memuat informasi mengenai haji. Informasi tersebut berupa data kualitatif jumlah jamaah dan kapal haji, biaya ibadah haji, pengalaman jamaah haji, masalah yang dihadapi jamaah haji, dan kebijakan pemerintah dalam mengatur ibadah haji.

Kesimpulan: Dalam penelitian ini penulis berpendapat bahwa surat kabar langka menyimpan banyak informasi mengenai penyelenggaraan ibadah haji pada zaman kolonial Belanda.
\end{abstract}

\title{
Kata Kunci: Jamaah haji, Perpustakaan Nasional Republik Indonesia, surat kabar langka
}

To cite this document

Supratman, F. R. (2020). Analyzing information of hajj pilgrimage in Indonesia in rare newspapers collection of National Library of Indonesia. Record and Library Journal, 6 (2), 189-198.

Open access under Creative Commons Attribution-Non Commercial-Share A like 4.0 International Licence 


\section{Pendahuluan}

Ibadah haji merupakan salah satu kewajiban yang harus ditunaikan oleh Muslim di seluruh dunia. Setiap tanggal 10 bulan Zulhijah (menurut kalender hijriah), Muslim dari seluruh dunia berkumpul di Kota Mekah, Arab Saudi, untuk melaksanakan beberapa kegiatan haji. Di antara kegiatan atau rukun haji yang harus dilaksanakan selama mengunjungi Mekah adalah ihram atau membaca niat untuk melaksanakan haji, wukuf di Padang Arafah, tawaf atau berjalan mengelilingi Kabah, sa'i atau berjalan kaki dari Bukit Shafa ke Marwa dan tahalul atau mencukur rambut. Kegiatan tersebut harus dilaksanakan dengan baik.

Ibadah haji atau naik haji sudah dilaksanakan sejak masa lampau. Beberapa hadis dan ayat Alquran telah menerangkan bagaimana pentingnya ibadah haji bagi umat Muslim. Rukun haji tidak berubah sejak masa nabi Muhammad SAW, hingga hari ini. Perubahan terhadap kegiatan haji teletak dalam interaksi antarmanusia, hingga perjalanannya. Jika pada masa lampau, perjalanan haji dilakukan menggunakan kapal laut atau menaiki unta dan kuda, maka pada masa kini haji dilaksanakan dengan pesawat. Meningkatnya populasi Muslim di seluruh dunia juga mempengaruhi kebijakan penguasa Mekah dalam mengatur kegiatan haji yang dilakukan satu tahun sekali. Indonesia merupakan salah satu negara Muslim terbesar di dunia. Untuk itu, pemerintah Indonesia selalu memberikan perhatian terhadap kegiatan ibadah haji yang dilakukan setiap Zulhijah. Sehingga, data dan informasi mengenai ibadah haji mutlak harus diketahui oleh pemerintah. Muslim Indonesia yang sedang mempersiapkan perjalanan haji juga, tentu saja, membutuhkan informasi yang tepat mengenai perjalanan dan kegiatan haji. Kebutuhan informasi mengenai ibadah haji mendorong penulis untuk melakukan penelitian mengenai penelusuran informasi mengenai ibadah haji melalui sumber pustaka yang ada di Perpustakaan Nasional Republik Indonesia.

Tujuan dari penelitian ini adalah untuk melakukan analisis terhadap sumber informasi mengenai ibadah haji pada zaman kolonial Belanda. Secara akademik, penelitian ini mencoba untuk memberikan sudut pandang baru dalam bidang ilmu perpustakaan. Selama ini, masih belum banyak penelitian ilmu perpustakaan yang membahas mengenai subjek tertentu dalam pendekatan ilmu sejarah. Padahal sejarawan dan pustakawan merupakan dua profesi yang sangat penting dalam menelusuri informasi. Dengan demikian, perpustakaan dan pustakawan pun dapat dimanfaatkan untuk melakukan penelitian sejarah (Setyaningsih, 2019). Secara objektif, penelitian ini bertujuan untuk memberikan kontribusi dalam memaparkan informasi yang tepat mengenai jamaah haji. Seringkali masyarakat mendapatkan informasi yang tidak tepat mengenai ibadah haji, khsususnya pada masa kolonial Belanda hingga masa Orde Baru. Terlebih lagi, berita bohong atau hoax banyak beredar di masyarakat dan menjadi masalah serius dalam masyarakat digital (Priatna, 2018). Untuk itu para pustakawan harus memiliki kemampuan literasi informasi yang baik terhadap berbagai macam subjek yang menjadi fokus pekerjaannya (Hasanah \& Rachman, 2019). Salah satu sumber informasi yang harus dipahami oleh pustakawan adalah surat kabar. Dari koleksi surat kabar langka, pustakawan dapat mengetahui berbagai informasi, khususnya informasi sejarah (Supratman, 2020). Dengan penelitian ini, pustakawan dapat menunjukan bagaimana cara melakukan penelusuran yang baik mengenai ibadah haji, khususnya pada periode kolonial Belanda. Dengan demikian, penulis ingin mengumpulkan dan menganalisa data mengenai haji pada masa kolonial Belanda agar bisa digunakan sebagai bahan pertimbangan kebijakan dalam mengelola kegiatan ibadah haji. Selain itu, data dan informasi yang diperoleh oleh penulis pun dapat digunakan oleh masyarakat untuk memberikan pengetahuan dan wawasan mengenai sejarah ibadah haji di Indonesia pada zaman kolonial Belanda. Untuk itu, dalam penelitian ini, penulis mengajukan beberapa rumusan masalah. Pertama, bagaimana melakukan penelusuran informasi mengenai ibadah haji zaman kolonial Belanda di Perpustakaan Nasional Republik Indonesia?; Mengapa surat kabar menjadi sumber penting yang memuat informasi ibadah haji?; Apa saja informasi mengenai ibadah haji yang terdapat di dalam surat kabar Indonesia?

Ruang lingkup penelitian ini mengenai penelusuran informasi tentang ibadah haji pada zaman kolonial Belanda. Dengan demikian, penulis fokus untuk mencari informasi mengenai ibadah haji. Namun, penulis hanya mencari informasi ibadah haji yang dilakukan pada zaman Belanda, bukan zaman Orde Lama, Orde Baru, atau Reformasi. Sumber informasi yang diteliti adalah surat kabar langka koleksi

To cite this document:

Supratman, F. R. (2020). Analyzing information of hajj pilgrimage in Indonesia in rare newspapers collection of National Library of Indonesia. Record and Library Journal, 6 (2), 189-198.

Open access under Creative Commons Attribution-Non Commercial-Share A like 4.0 International Licence

(CC-BY-SA) (c) (P) (?) 
Perpustakaan Nasional Republik Indonesia. Surat kabar langka adalah surat kabar yang diterbitkan di Indonesia sejak abad ke-19 hingga awal abad ke-21. Ruang lingkup surat kabar langka koleksi Perpustakaan Nasional RI adalah koleksi dari tahun 1816 hingga 2015.

Penelitian mengenai ibadah haji sudah banyak dilakukan oleh para peneliti, baik peneliti Indonesia maupun luar Indonesia. Kebanyakan penelitian yang dilakukan adalah mengenai perjalanan haji. Dauphin, Jeddou dan Castex (2015), meneliti mengenai rute perjalanan haji yang dipakai pada masa lampau. Para peneliti tersebut meneliti menggunakan data literatur, arkeologis, hingga kartografi. Selain itu, terdapat penelitian mengenai ibadah haji dalam perspektif kesehatan. Hubungan haji dan kesehatan memang cukup kuat. Alfelali, Khandaker, Booy, dan Rashid (2015) melakukan penelitian mengenai data epidemologi influenza pada jamaah haji sejak tahun 2003. Kemudian penelitian dari Parker (2015) juga menujukkan bagaimana kaitan antara para jamaah haji dari Afrika Selatan dengan epidemik. Dengan demikian, penelitian tersebut membicarakan kegiatan ibadah haji dalam perspektif ilmu kesehatan. Dalam literatur kesarjanaan di Indonesia, penelitian mengenai ibadah haji sudah banyak ditulis dalam berbagai aspek dan perspektif. Istianah (2016), menulis ritual ibadah haji dan makna kegiatan atau rukunnya. Selain dari perspektif teologi, ibadah haji juga ditinjau dari perspektif hukum. Ruswandana, Turisno, dan Suharto (2016), meneliti mengenai perlindungan terhadap konsumen dalam membatalkan keberangkatan haji.

Berdasarkan beberapa hasil penelitian sebelumnya yang ditemukan, maka penulis menemukan bahwa sedikit penelitian haji yang ditinjau dari perspektif ilmu perpustakaan dan informasi. Dengan demikian, penelitian ini akan menjelaskan bagaimana ibadah haji pada zaman kolonial Belanda ditinjau dari perspektif ilmu perpustakaan dan informasi. Dalam hal ini, penulis akan meninjau informasi haji melalui bahan pustaka surat kabar langka. Hal tersebut, bertujuan untuk memudahkan penulis dalam menelusuri informasi yang akuat. Berdasarkan penelitian ini, penulis berargumen bahwa surat kabar pada awal abad ke-20, banyak yang memberitakan mengenai ibadah haji karena jumlah jamaah haji Indonesia jumlahnya sangat banyak dan berkontribusi terhadap pemasukan ekonomi pemerintah kolonial. Informasi tersebut tersebar di berbagai surat kabar yang bermarkas di Pulau Jawa, khususnya Batavia.

\section{Metode Penelitian}

Penelitian ini menggunakan metode deskriptif. Melalui metode ini, penulis didorong untuk memaparkan dan menggambarkan dengan detail segala aspek yang berkaitan dengan haji, seperti latar belakang, dan perkembangan historis ibadah haji. Selain itu, penulis juga menggambarkan bagaimana peran surat kabar awal abad ke-20, dalam memberikan informasi dan berita mengenai ibadah haji dan apa saja informasi yang didapat melalui surat kabar tersebut. Dengan demikian, penulis akan menganalisis satu persatu data dan informasi mengenai ibadah haji yang terdapat di dalam surat kabar. Pendekatan saintifik untuk melakukan penelitian ini adalah pendekatan ilmu sejarah. Dalam artikel ini, penulis berusaha melakukan analisis terhadap informasi dengan menggunakan perspektif ilmu sejarah sehingga penulis memperhatikan dengan baik konteks politik, sosial, dan ekonomi Hindia Belanda awal abad ke20 dalam menganalisa informasi mengenai ibadah haji. Dalam penelitian ini, penulis mengumpulkan 72 artikel dari 22 surat kabar yang terbit antara tahun 1909-1933. Surat kabar tersebut merupakan koleksi Layanan Kelompok Khusus, Perpustakaan Nasional Republik Indonesia.

\section{Hasil dan Diskusi}

Haji merupakan kegiatan yang wajib dilakukan oleh Muslim. Jika seorang Muslim memiliki kemampuan ekonomi dan kesehatan, mereka harus menunaikan ibadah haji, setidaknya satu kali selama seumur hidup. Menurut bahasa, "haji" berarti mengunjungi, ziarah, atau menuju kepada lokasi tertentu. Secara makna, haji merupakan upaya yang dilakukan oleh Muslim untuk mengunjungi Mekah dalam rangka menunaikan ibadah haji yang telah ditetapkan berdasarkan peraturan agama. Peraturan dalam agama Islam, biasanya ditetapkan berdasarkan Alquran, hadis, dan pendapat ulama. Dengan demikian, ibadah haji dilakukan oleh seluruh Musim di dunia tanpa memandang suku, ras, dan bahasa.

Sejak Islam masuk ke Indonesia pada abad ke-13, banyak Muslim Indonesia yang melaksanakan

To cite this document:

Supratman, F. R. (2020). Analyzing information of hajj pilgrimage in Indonesia in rare newspapers collection of National Library of Indonesia. Record and Library Journal, 6 (2), 189-198.

Open access under Creative Commons Attribution-Non Commercial-Share A like 4.0 International Licence

(CC-BY-SA) (c) (i) (2) 
ibadah haji ke Mekah. Mereka terdiri dari para pedagang, petani, nelayan, hingga anggota kesultanan dan kerajaan. Menurut manuskrip dari Yaman, jamaah Asia Tenggara dari Jawa datang pertama kali ke Hijaz (Mekah dan Madinah) antara tahun 1227 dan 1367 (Tagliacozzo, 2013). Sebelum tahun 1800, jamaah haji dari Nusantara datang ke Mekah dengan menggunakan kapal layar melintasi Samudera Hindia. Para jamaah haji tersebut menuliskan pengalaman mereka dalam bentuk catatan yang sekarang tersimpan di berbagai perpustakaan. Kapal laut merupakan sarana utama yang digunakan untuk mengangkut jamaah haji. Dalam mengarungi lautan, jamaah haji Indonesia harus menghadapi berbagai macam rintangan, seperti bajak laut. Hikayat Hang Tuah menunjukan bahwa bajak laut merupakan komunitas yang banyak ditemukan di Selat Malaka, khususnya Singapura (Saputra, Priyadi \& Wartiningsih, 2017). Informasi mengenai catatan-catatan jamaah haji Nusantara banyak tersimpan di berbagai perpustakaan, khususnya Perpustakaan Nasional Republik Indonesia. Koleksi tersebut biasanya disimpan di Kelompok Naskah Nusantara.

Perjalanan yang dilakukan oleh jamaah haji Indonesia terus dilakukan hingga memasuki awal abad ke-20. Pada masa ini, pemerintah kolonial Belanda masih memiliki kekuasaan di Indonesia. Pemerintah kolonial memiliki otoritas untuk mengatur perjalanan haji dari Hindia Belanda ke Mekah. Para sejarawan dan pustakawan yang tertarik meneliti naik haji pada zaman kolonial Belanda pada awal abad ke-20 dapat menelusuri informasi melalui surat kabar langka yang berada di Perpustakaan Nasional Republik Indonesia. Selain Perpustakaan Nasional, ada juga institusi lain yang memiliki koleksi surat kabar langka, seperti Museum Pers di Solo. Meskipun demikian, penelitian ini akan menelusuri informasi mengenai ibadah haji zaman kolonial Belanda melalui sumber surat kabar langka yang dimiliki oleh Perpustakaan Nasional.

Berdasarkan survei terhadap surat kabar langka di Perpustakaan Nasional, penulis menemukan 72 data mengenai kegiatan ibadah haji pada zaman kolonial Belanda. Data tersebut, tersebar di dalam 22 surat kabar. Dengan demikian, penulis telah melakukan survei terhadap 22 surat kabar langka yang terbit pada awal abad ke-20. Berikut adalah data mengenai nama-nama surat kabar dan artikel yang memuat data dan informasi mengenai kegiatan naik haji pada zaman kolonial Belanda.

Tabel 1. Surat kabar dan jumlah artikel yang memuat informasi mengenai haji

\begin{tabular}{lll}
\hline No & Nama Surat Kabar & $\begin{array}{l}\text { Jumlah } \\
\text { Artikel }\end{array}$ \\
\hline $\mathbf{1}$ & Darmokondo & 3 \\
$\mathbf{2}$ & Kaoem Kita & 4 \\
$\mathbf{3}$ & Kaoem Moeda & 8 \\
$\mathbf{4}$ & Kemadjoean Hindia & 3 \\
$\mathbf{5}$ & Keng Po & 3 \\
$\mathbf{6}$ & Lasjkar & 2 \\
$\mathbf{7}$ & Mustika & 1 \\
$\mathbf{8}$ & Oetoesan Hindia & 17 \\
$\mathbf{9}$ & Pelita Andalas & 2 \\
$\mathbf{1 0}$ & Pemandangan & 3 \\
$\mathbf{1 1}$ & Pemberita Betawi & 2 \\
$\mathbf{1 2}$ & Pemberita Makasar & 2 \\
$\mathbf{1 3}$ & Peroendingan & 1 \\
$\mathbf{1 4}$ & Pertja Selatan & 1 \\
$\mathbf{1 5}$ & Pewarta Deli & 6 \\
$\mathbf{1 6}$ & Radio & 1 \\
$\mathbf{1 7}$ & Sinar Djawa & 3 \\
$\mathbf{1 8}$ & Sinar Hindia & 1 \\
$\mathbf{1 9}$ & Sinar Sumatra & 3 \\
$\mathbf{2 0}$ & Soeara Islam & 2 \\
$\mathbf{2 1}$ & Soeara Kalimantan & 1 \\
$\mathbf{2 2}$ & Soeara Oemoem & 2 \\
\hline
\end{tabular}

To cite this document:

Supratman, F. R. (2020). Analyzing information of hajj pilgrimage in Indonesia in rare newspapers collection of National Library of Indonesia. Record and Library Journal, 6 (2), 189-198.

Open access under Creative Commons Attribution-Non Commercial-Share A like 4.0 International Licence 


Sumber: hasil penelitian Februari 2020.

Berdasarkan tabel tersebut, maka penulis menemukan bahwa informasi mengenai ibadah haji paling banyak terdapat pada surat kabar Oetoesan Hindia. Surat kabar Oetoesan Hindia memuat 17 artikel mengenai kegiatan ibadah haji pada awal abad ke-20. Surat kabar ini merupakan media propaganda yang dimiliki oleh Sarekat Islam (SI), organisasi Islam modern pertama di Indonesia (Supratman, 2017). Tokoh SI yang sangat terkenal di Indonesia adalah H.O.S. Cokroaminoto. Dia merupakan pemimpin SI yang banyak menarik perhatian rakyat, sehingga SI memiliki pengikut yang banyak dari kalangan buruh dan petani di pedesaan. Selain menjabat sebagai ketua SI, Cokroaminoto juga menjadi editor pada surat kabar Oetoesan Hindia. SI memperjuangkan hak-hak Muslim yang ditindas oleh pemerintah kolonial Belanda. Dengan demikian, surat kabar Oetoesan Hindia juga ikut memperjuangkan hak-hak Muslim pada awal abad ke-21. Salah satu perjuangan dari Oetoesan Hindia adalah memperjuangkan nasib jamaah haji Indonesia yang ada di Mekah.

Artikel yang ditemukan oleh penulis terdiri dari berbagai macam data. Surat kabar memberitakan banyak sekali data mengenai jumlah jamaah haji pada tahun tertentu, nama-nama kapal yang berangkat ke Mekah, detail perjalanan kapal haji, pengalaman hidup di Mekah, hingga permasalahan yang dihadapi oleh jamaah haji Indonesia di Mekah. Penulis membagi informasi yang ditemukan di dalam surat kabar menjadi empat bagian: Informasi kuantitatif jamaah dan kapal haji, informasi biaya ibadah haji, pengalaman perjalanan haji, masalah yang dihadapi jamaah haji, kebijakan pemerintah kolonial terhadap jamaah haji Indonesia.

Data yang paling krusial mengenai jamaah haji Indonesia pada masa kolonial adalah data kuantitatif mengenai jumlah jamaah dan kapal haji yang berangkat dari Indonesia ke Mekah. Data ini sangat bermanfaat untuk menghitung berapa jumlah jamaah haji yang berangkat ke Mekah dari masa ke masa. Data tertua mengenai jumlah jamaah haji didapat dari surat kabar Pemberita Betawi pada 10 Februari 1909. Menurut surat kabar tersebut, terdapat kereta api Malang yang membawa 1000 jamaah haji dari Jedah. Para jamaah haji tersebut dicurigai terinfeksi penyakit pes. Surat kabar Kaoem Moeda pada 17 Maret 1927 juga memuat informasi mengenai statistik jamaah haji asal Bandung. Menurut statistik Kaoem Moeda, pada tahun 1925 jumlah jamaah haji asal Bandung terdiri dari 29 jamaah haji yang terdiri dari 25 jamaah laki-laki dan 4 jamaah perempuan. Kemudian, pada tahun 1926 jumlah jamaah haji asal Bandung meningkat drastis menjadi 850 orang yang terdiri dari 251 jamaah perempuan dan 599 jamaah laki-laki. Pada zaman depresi ekonomi tahun 1930'an, jumlah jamaah haji semakin menurun dengan tajam. Surat kabar Pemberita Makassar tanggal 4 Januari 1933 memberitakan mengenai turunnya jumlah jamaah haji asal Malang. Pada tahun 1929 jumlah jamaah haji asal Malang berjumlah 223 orang, tapi pada tahun 1932 jumlah jamaah haji berkurang menjadi 18. Selain itu ada juga informasi dari surat kabar Pelita Andalas yang mengumumkan penurunan jumlah jamaah haji Indonesia pada saat zaman depresi ekonomi tahun 1930 'an. Menurut informasi dari Pelita Andalas, sebelumnya ada malaise (depresi ekonomi) banyaknya orang yang pergi ke Mekah berjumlah 25.000. Sekarang hanya kurang lebih 2.000 orang saja.

Selain memberikan informasi kuantitatif mengenai jumlah jamaah haji, surat kabar juga mmberikan informasi mengenai jumlah kapal yang berangkat dari Indonesia ke Jedah, dan sebaliknya. Menurut Eric Tagliacozzo (2016), biaya perjalanan haji melalui laut lebih murah daripada transportasi darat. Sejak pertengahan abad ke-19, kapal layar sudah digantikan oleh kapal uap. Selain itu, banyak pengusaha, khususnya orang Arab, yang membuka usaha pelayaran haji. Iklan dalam surat kabar Pewarta Deli pada 19 November 1923 menunjukan sebuah biro perjalanan haji bernama Stoomvart Mij, Nederland. Kapal-kapal yang dimiliki perusahaan tersebut akan berangkat dari Pelabuhan Belawan. Iklan tersebut menunjukan nama-nama kapal, seperti S.S. Karimoen, S.S. Karimata, S.S. Sembilan, dan S.S.Krakatau. Surat kabar Pelita Andalas juga menyebutkan bahwa sebelum terjadinya depresi ekonomi, Indonesia bisa mengirim 40 kapal untuk pergi ke Mekah. Namun, ketika terjadi depresi ekonomi, hanya ada 3 kapal yang berangkat dari Pelabuhan Tanjung Priok.

Kapal-kapal haji yang diinformasikan dalam surat kabar merupakan perusahaan milik asing.

To cite this document:

Supratman, F. R. (2020). Analyzing information of hajj pilgrimage in Indonesia in rare newspapers collection of National Library of Indonesia. Record and Library Journal, 6 (2), 189-198.

Open access under Creative Commons Attribution-Non Commercial-Share A like 4.0 International Licence

(CC-BY-SA) (c) (i) (2) 
Sebelum tahun 1930, tidak ada kapal dan biro perjalanan haji yang dimiliki oleh pribumi. Muhammadiyah, organisasi Islam modern, menginginkan agar orang pribumi pergi ke Mekah melalui biro perjalanan dan kapal haji yang dimiliki oleh pribumi. Artikel dari surat kabar Pertja Selatan pada tanggal 14 Maret 1931 menunjukan adanya keinginan Muhammadiyah membentuk biro perjalanan haji sendiri. Menurut artikel tersebut, Kongres Muhammadiyah tahun lalu (1930) di Sumatra berpendapat bahwa jamaah haji Indonesia harus memiliki kapal mereka sendiri. Namun, diakui oleh Muhammadiyah, hal tersebut akan sangat sulit karena pelayaran dimonopoli oleh Belanda. Meskipun demikian, Muhammadiyah akan tetap berusaha mendirikan biro perjalanan haji sendiri.

Surat kabar Indonesia pada awal abad ke-20, juga banyak menginformasikan mengenai biaya yang dibutuhkan oleh jamaah haji asal Indonesia. Surat kabar Kaoem Moeda tanggal 3 Januari 1923 memberikan informasi mengenai kebutuhan jamaah haji Indonesia selama di Mekah. Menurut surat kabar tersebut, beberapa kebutuhan hidup yang harus dimiliki setelah sampai di Jedah adalah: beras satu pikul (f.4), biaya sewa pondokan, perahu, tikar, dan kuli (f.4.70), biaya sewa unta (f.28), biaya pemandu atau syaikh (f.21). Dari Jedah, para jamaah haji naik unta ke Mekah. Setelah datang di Mekah, mereka harus membayar kuli angkut (f.0.50), sewa rumah (f.14), biaya makan (f.49), Aloetawif atau pemandu (f.1), air zamzam (f.60). Setelah selesai melaksanakan ibadah haji di Mekah, para jamaah yang ingin pergi ke Madinah harus membayar ongkos transportasi. Mereka harus naik unta dari Mekah ke Madinah dengan membayar sebesar f.112. Selain itu, masih banyak biaya yang harus dikeluarkan oleh jamaah haji Indonesia selama tinggal di Mekah dan Madinah, seperti membeli roti jamal (f.4), kurma (f.1.60), gula (f.4), dan lain-lain. Berdasarkan informasi dari surat kabar Kaoem Moeda, biaya total yang harus dikeluarkan jamaah haji asal Indonesia selama di Mekah dan Madinah adalah sebesar f.187,60.

Selain informasi kuantitatif mengenai jumlah jamaah dan kapal haji, artikel surat kabar banyak memuat mengenai pengalaman para jamah haji Indonesia dalam melaksanakan ibadah haji. Pengalaman jamaah haji Indonesia banyak diberitakan oleh surat kabar, agar orang-orang Indonesia dapat mengetahui bagaimana persiapan sebelum berangkat haji, berapa uang yang harus dipersiapkan, bagaimana mempersiapkan perjalanan dengan kapal laut, apa yang harus dilakukan begitu sampai di Mekah dan bagaimana cara mereka kembali ke Indonesia. Surat kabar Kaoem Kita pada 14 Agustus 1924 memberitakan mengenai pengalaman Bupati Bandung R.T.A.A. Wiranatakusumah. Dalam surat kabar tersebut, diberitakan bahwa sesampainya di Mekah, Wiranatakusumah disambut oleh Raja Hijaz, yaitu Raja Husein, karena konsul Belanda di Mekah telah memberitahu kepada raja mengenai kedatangan Bupati Bandung tersebut. Di dalam berita juga memperlihatkan bagaimana Wiranatakusumah melakukan tawaf mengelilingi Kabah bersama dengan Raja Husein. Hampir seluruh kegiatan Wiranatakusumah diberitakan, termasuk keadaan ketika tinggal di Arafah. Pada saat Idul Adha, R.T.A.A. Wiranatakusumah diizinkan untuk mengunjungi Raja Husein. Sebelum bertemu raja, baju Wiranatakusumah dihias dengan bintang dari menteri. Setelah itu Wiranatakusumah dapat bertemu dan berbicara langsung dengan Raja Huesin.

Artikel-artikel yang disurvei oleh penulis, juga banyak memuat informasi mengenai permasalahan-permasalahan yang dihadapi oleh jamaah haji asal Indonesia. Pada awal abad ke-20, banyak masalah yang dihadapi, seperti penipuan yang dilakukan oleh syaikh (pemandu haji), biaya mahal, penyakit menular, perang, perampokan yang dilakukan oleh suku badui di Arab. Beberapa permasalahan tersebut harus diselesaikan oleh pemerintah kolonial Belanda. Untuk itu, pemerintah kolonial Belanda memiliki kantor Konsulat Jenderal Belanda di Jedah. Tugas konsulat tersebut adalah untuk melakukan kontrol dan perlindungan terhadap jamaah haji asal Indonesia di Mekah dan Madinah. Konsulat Jenderal Belanda di Jedah juga mempekerjakan pribumi Indonesia sebagai penerjemah. Salah satu petugas pribumi yang pernah bekerja di Konsulat Belanda di Jedah adalah Raden Aboe Bakar Djajadiningrat (1854-1914) (Rohmana, 2016). Aboe Bakar Djajadiningrat adalah informan utama untuk Snouck Hurgronje, orientalis Belanda, ketika dia datang ke Mekah untuk meneliti jamaah haji Indonesia.

Salah satu permasalahan yang diangkat dalam artikel surat kabar adalah Perang Dunia I. Perang Dunia I terjadi pada tahun 1914 dan berakhir pada 1918. Ketika Perang Dunia I, Mekah dan Madinah berada di bawah kekuasaan Negara Usmani. Setelah bergabung bersama Jerman, Usmani

To cite this document:

Supratman, F. R. (2020). Analyzing information of hajj pilgrimage in Indonesia in rare newspapers collection of National Library of Indonesia. Record and Library Journal, 6 (2), 189-198.

Open access under Creative Commons Attribution-Non Commercial-Share A like 4.0 International Licence

(CC-BY-SA) (C) (P) (?) 
mendeklarasikan perang melawan Inggris, Prancis, dan Rusia. Perang telah menghancurkan kehidupan sosial dan ekonomi di Mekah. Menurut surat kabar Oetoesan Hindia tanggal 13 Apri 1915, kehidupan di Mekah menjadi sangat sulit karena harga barang menjadi naik. Perang Dunia I juga mengakibatkan terputusnya lalu lintas laut antara Asia Tenggara dan Jedah. Hal tersebut, menyebabkan kapal-kapal haji berhenti beroperasi. Jika ada yang beroperasi, maka jumlahnya sangat sedikit. Perang juga menyebabkan banyak jamaah haji asal Indonesia yang terlantar di Mekah. Selama Perang Dunia I, banyak jamaah haji yang kekurangan uang. Menurut surat kabar Oetoesan Hindia tanggal 1 Mei 1915, para jamaah haji Indonesia biasanya mendapatkan uang dari keluarga mereka di Indonesia. Karena perang sedang berkecamuk, maka keluarga mereka tidak dapat mengirimkan uang untuk mereka. Sejak perang dimulai, tidak ada lagi kapal yang berlayar dari Indonesia ke Jedah sehingga kiriman uang menjadi terhenti. Akibatnya, banyak jamaah haji yang terpaksa berhutang.

Untuk itu, masyarakat di Batavia membentuk komite untuk menolong jamaah haji di Mekah. Artikel Oetoesan Hindia tanggal 18 Juni 1915 menunjukan bahwa komite telah dibentuk untuk menolong para jamaah haji Indonesia di Mekah. Komite mengumpulkan uang dari keluarga para jamaah haji dan masyarakat. Berkat usaha dari komite, mereka dapat mengumpulkan uang sebesar f.60.000. Menurut artikel tersebut, orang-orang Belanda dan Tionghoa juga berpartisipasi dalam memberikan uang untuk menolong jamaah haji Indonesia yang tinggal di Mekah. Bahkan artikel tersebut juga memberikan informasi mengenai orang-orang yang mendermakan uangnya. Diantara daftar orang yang mendermakan uangnya adalah: Seorang Belanda asal Bandung (f. 10), N.N. Waltevreden (f.50), Moeh. Thabrie asal Waltevreden, Batavia (f. 12,50), M. Kromodiardjo, Cibadak (f.1), M. Kartadiwangsa, Cibadak (f.0,25), M. Soeradimedja, Cibadak (f.0,25), seorang dari Kudus (f.0,25), G.H. de M. Kalisetail dari Banyuwangi (f.3), dan pegawai Volkslectuur dari Waltevreden, Batavia (f.7,25).

Selain masalah perang, para jamaah haji Indonesia juga harus menghadapi masalah penyakit yang melanda dunia pada awal abad ke-20. Salah satu penyakit menular yang menginfeksi jamaah haji adalah kolera. Pada pertengahan abad ke-19, kolera mulai muncul di India. Kolera kemudian menyebar dari India ke Arab sehingga menyebabkan kematian 15.000 jamaah haji (Boyle, 2015). Surat kabar Oetoesan Hindia pada tanggal 16 Januari 1915 menyebutkan bahwa sebelum datang ke Mekah, jamaah haji Indonesia disuntik dulu untuk menghilangkan penyakit kolera. Wabah kolera merupakan penyakit yang mematikan. Surat kabar Oetoesan Hindia menyebut bahwa pada 1913 wabah kolera menginfeksi jamaah haji. Jumlah kematian akibat kolera mengakibatkan kematian pada 14 persen jamaah haji. Sedangkan pada 1914, 11 persen jamaah haji meninggal akibat penyakit kolera. Diantara mereka yang wafat merupakan jamaah haji asal Indonesia. Selain penyakit kolera, cuaca yang panas juga banyak menyebabkan kematian. Menurut surat kabar Oetoesan Hindia 16 Januari 1915, terdapat 200 orang Jawa yang meninggal dalam perjalanan ke Madinah akibat cuaca yang sangat panas. Selain kolera, penyakit pes merupakan penyakit berbahaya yang dapat menyebabkan kematian. Penyakit pes mulai timbul di Jedah sejak awal 1913. Penyakit tersebut terus menyebar sampai bulan Mei 1913.

Permasalahan ibadah haji yang diberitakan oleh surat kabar pada awal abad ke-20 adalah masalah penipuan. Para calon jamaah haji kerap kali selalu menjadi korban penipuan yang menyebabkan mereka kehilangan banyak uang. Para penipu biasanya menyamar menjadi seorang makelar (badal haji). Pada musim haji biasanya banyak makelar yang pergi ke desa-desa untuk menawarkan bantuan dalam mempersiapkan perjalanan haji. Para makelar seringkali memanfaatkan kepolosan dari calon jamaah haji, sehingga mereka dengan mudah melakukan penipuan dan penggelapan uang. Surat kabar Keng Po tanggal 18 Februari 1932 menceritakan adanya penipuan yang dilakukan oleh makelar di Bogor. Korban penipuan ini berjumlah 20 orang. Penipu tersebut meminta uang sebesar f.175 kepada 20 orang tersebut, dengan imbalannya mereka akan dibantu untuk berangkat ke Mekah. Surat kabar Oetoesan Hindia tanggal 15 Januari 1915 menceritakan mengenai adanya penipuan yang dilakukan oleh seorang makelar haji yang bernama Haji Banjir dari Batavia. Haji Banjir melakukan penipuan terhadap dua belas calon jamaah haji dari Bandung. Mereka memberikan uang sebesar f.10 kepada Haji Banjir karena dibujuk untuk menggunakan pemandu yang disedikan oleh Haji Banjir, yaitu Syaikh Hamid Chadidjah Aboesjahin. Menurut artikel tersebut, banyak orang-orang yang ingin melakukan penipuan terhadap para jamaah haji.

To cite this document:

Supratman, F. R. (2020). Analyzing information of hajj pilgrimage in Indonesia in rare newspapers collection of National Library of Indonesia. Record and Library Journal, 6 (2), 189-198.

Open access under Creative Commons Attribution-Non Commercial-Share A like 4.0 International Licence

(CC-BY-SA) (c) (i) (2) 
Banyak jamaah haji yang dimintai uang untuk membeli tiket kapal sehingga seringkali terdapat jumlah jamaah haji lebih banyak daripada tempat duduk yang tersedia di kapal. Tugas kantor Konsulat Jenderal Belanda di Jedah adalah untuk melindungi para jamaah haji asal Indonesia dari perbuatan penipu. Namun, sedikit jamaah haji yang mau melaporkan kasus penipuan kepada konsulat.

Selain penipuan, jamaah haji asal Indonesia juga sering menjadi korban perampokan dan penyerangan yang dilakukan oleh suku badui. Suku badui merupakan kelompok suku nomaden yang hidup di gurun pasir. Penguasa Mekah, Syarif Mekah, biasanya memberikan uang kepada suku badui agar mereka tidak mengganggu perjalanan jamaah haji. Namun, banyak suku badui yang masih mengganggu perjalanan jamaah haji. Surat kabar Kemadjoean Hindia tanggal 4 September 1923 menyebutkan bahwa kelompok jamaah haji Indonesia diberhentikan oleh suku badui. Mereka meminta uang kepada jamaah haji sebanyak f.3. Suku badui memang selalu mengganggu jamaah haji yang melintasi wilayah mereka. Jika melihat kawanan jamaah haji, suku badui akan memberhentikannya dan meminta uang. Hal ini, membuat para jamaah haji Indonesia sering kehabisan uang karena harus memberikan uang kepada suku badui.

Surat kabar Indonesia awal abad ke-20, juga banyak memberitakan mengenai kebijakan-kebijakan pemerintah kolonial Belanda dalam mengatur ibadah haji. Surat kabar Soeara Oemoem tanggal 6 Oktober 1938, misalnya, menyebutkan bahwa pemerintah membolehkan jamaah haji Indonesia membayar biaya haji dengan emas yang setara dengan f.1000. Surat kabar Sinar Sumatra tanggal 19 Maret 1926 memberikan informasi detail mengenai peraturan-peraturan yang harus ditaati oleh calon jamaah haji. Artikel pertama menyatakan bahwa calon jamaah haji yang ingin berangkat ke Mekah harus mendapatkan surat izin dari kepala regentschap (untuk Jawa dan Madura) dan kepala ondeerafdeling (untuk luar Jawa). Art kedua ikel menyatakan bahwa sebelum diberikan surat izin, kepala regentschap atau ondeerafdeling harus meminta keterangan kepada kepala desa. Artikel ketiga, menyebutkan bahwa sebelum berangkat ke Mekah, surat izin tersebut harus dicap oleh havenmeester (kepala pelabuhan) di Indonesia. Jika mereka berangkat dari luar negeri, surat izin tersebut harus dicap di Konsulat Jenderal Belanda di Jedah. Setelah sampai di Jedah, surat izin tersebut harus diserahkan kepada Konsulat. Setelah pulang ke Indonesia, jamaah haji harus melapor kepada kepala regentschap atau ondeerafdeling. Artikel kelima, menyebutkan bahwa, jika jamaah haji Indonesia yang pulang dari Mekah tidak dapat menunjukan surat izin perjalanan, maka mereka akan didenda sebesar f.100. Artikel keenam, menyebutkan bahwa, kepala regentschap atau ondeerafdeling harus memiliki catatan mengenai keberangkatan dan kedatangan jamaah haji. Artikel ketujuh, menyatakan bahwa peraturan ini diterapkan sejak tahun 1927.

\section{Simpulan}

Berdasarkan penelitian ini, penulis menemukan ada 22 surat kabar langka yang memuat informasi mengenai ibadah haji pada zaman kolonial Belanda. Kebanyakan informasi haji dapat ditemukan di surat kabar Oetoesan Hindia. Meskipun demikian, beberapa surat kabar lain, seperti Kaoem Moeda, Pewarta Deli, Pelita Andalas, dan lain-lain, juga banyak menyimpan informasi mengenai ibadah haji pada zaman kolonial Belanda. Surat kabar tersebut banyak menyimpan informasi mengenai ibadah haji karena Indonesia merupakan negara Muslim terbesar di dunia. Atas hal tersebut, kegiatan ibadah haji memberikan dampak yang signifikan terhadap kehidupan politik, sosial, dan ekonomi. Informasi mengenai jamaah haji Indonesia dalam surat kabar mencakup lima aspek, yaitu informasi kualitatif mengenai jumlah jamaah, dan kapal, informasi mengenai biaya haji, pengalaman perjalanan jamaah haji, permasalahan yang dihadapi oleh jamaah haji dan kebijakan pemerintah kolonial Belanda dalam mengatur jamaah haji Indonesia.

\section{Referensi}

Alfelali, M., Khandaker, G., Booy, R., \& Rashid, H. (2015). Mismatching between circulating strains and vaccine strains of influenza: Effect on Hajj pilgrims from both hemispheres. Human Vaccines and Immunotherapeutics, 12(3), 709-715. https://doi.org/10.1080/21645515.2015.1085144

Boyle, S.A. (2015). Cholera, Colonialism, and Pilgrimage: Exploring Global/Local Exchange in the

To cite this document:

Supratman, F. R. (2020). Analyzing information of hajj pilgrimage in Indonesia in rare newspapers collection of National Library of Indonesia. Record and Library Journal, 6 (2), 189-198.

Open access under Creative Commons Attribution-Non Commercial-Share A like 4.0 International Licence

(CC-BY-SA) (c) (i) (2) 
Central Egyptian Delta, 1848-1907. Journal of World History, 26(3), 581-604. http://eresources.perpusnas.go.id:2367/eds/pdfviewer/pdfviewer?vid=0\&sid=741d3ff0-f883-4f87-8d22af12a4b10654\%40sdc-v-sessmgr03

Dauphin, C., Jeddou, M.B., \& Caltex, J.M. (2015). To Mecca on Pilgrimage on Foot and Camel-back. Bulletin for the Council for British Research in the Levant, 10(1), 23-36. https://doi.org/10.1179/1752726015Z.00000000029

Hasanah, A. \& Rachman, M. A. (2019), Librarian's information literacy skills to fulfilling library users' needs a public library in Bogor, Indonesia. Record and Library Journal, 5(1), 22-32. http://dx.doi.org/10.20473/rlj.V5-I1.2019.22-32

Istaniah. (2016). Prosesi Haji dan Maknanya. Esoterik: Jurnal Akhlak dan Tasawuf, 2(1), 30-44. http://dx.doi.org/10.21043/esoterik.v2i1.1900

Parker, S. (2010). The Hajj: a constant travel destination amidst changing times.Southern African Journal of Epidemiology and Infection, 15(1), 14-18. https://doi.org/10.1080/10158782.2010.11441371

Priatna, Y. (2018). Hoax: An information society challange."Record and Library, 4(2), 92-98. http://dx.doi.org/10.20473/rlj.V4-I2.2018.92-98

Rohmana, J. A. (2016). Persehabatan Penjajah dan Bangsa Jajahan di Hindia Belanda: Snouck Hurgronje dan Haji Hasan Mustapa. Jurnal Afkaruna, 12(2), 144-168. https://journal.umy.ac.id/index.php/afkaruna/article/view/2788/2671

Ruswandana, N.V., Sutrisno, B.E., \& Suharto. (2016). Perlindungan Hukum Terhadap Konsumen dalam Pembatalan Keberangkatan Ibadah Haji Khusus oleh Biro Penyelenggara Ibadah Haji Khusus. Diponegoro Law Journal, 5(3), 1-12. https://www.neliti.com/id/publications/19315/perlindunganhukum-terhadap-konsumen-dalam-pembatalan-keberangkatan-ibadah-haji

Saputra, F.I.G., Priyadi, A.T., \& Wartiningsih, A. (2017). Kajian Strukturalisme dan Nilai-Nilai pada Hikayat Hang Tuah Jilid 1 Karya Muhammad Haji Saleh. Jurnal Pendidikan dan Pembelajaran Khatulistiwa, 6(5), 1-14. http://jurnal.untan.ac.id/index.php/jpdpb/article/view/20156/16542

Setyaningsih, W. (2019). Mengulik sejarah melalui pemanfaatan perpustakaan. Pustabiblia, 3(2), 205-222. https://doi.org/10.18326/pustabiblia.v3i2.205-222

Supratman, F.R. (2017). Rafet Bey: The Last Ottoman Consul in Batavia during the First World War 1911-1924. Studia Islamika, 24(1), 33-67. http://journal.uinjkt.ac.id/index.php/studiaislamika/article/view/3684

Supratman, F.R. (2020). Koleksi surat kabar langka Perpustakaan Nasional Republik Indonesia sebagai sumber penelitian sejarah global. Jurnal Kajian Informasi dan Perpustakaan, 8 (1), 85-100. https://doi.org/10.24198/jkip.v8i1.25212

Tagliacozzo, E. (2013). Longest Journey: Southeast Asians and the Pilgrimage to Mecca. New York: Oxford University Press.

Tagliacozzo, E. (2016). The Hajj by Sea. in Eric Tagliacozzo \& Shawkat M. Toorawa (ed). The Hajj: Pilgrimage in Islam (pp.113-130) New York: Cambridge University Press.

To cite this document:

Supratman, F. R. (2020). Analyzing information of hajj pilgrimage in Indonesia in rare newspapers collection of National Library of Indonesia. Record and Library Journal, 6 (2), 189-198.

Open access under Creative Commons Attribution-Non Commercial-Share A like 4.0 International Licence

(CC-BY-SA) (c) (i) (2) 